\title{
Geographical Perspectives on Epidemic Transmission of Cholera in Haiti, October 2010-March 2013
}

\author{
Matthew Smallman-Raynor ${ }^{*}$, Andrew Cliff $^{\dagger}$ and Anna Barford ${ }^{\dagger}$
}

$\underline{\text { Affiliations }}$

*School of Geography, University of Nottingham, University Park, Nottingham, NG7 2RD, U.K.

†Department of Geography, University of Cambridge, Downing Place, Cambridge, CB2 3EN, U.K.

Correspondence: School of Geography, University of Nottingham, University Park, Nottingham NG7 2RD, U.K., e-mail: matthew.smallman-raynor@nottingham.ac.uk (Smallman-Raynor); Department of Geography, University of Cambridge, Downing Place, Cambridge CB2 3EN, U.K., e-mail: adc2@cam.ac.uk (Cliff) and ab423@cam.ac.uk (Barford).

Running head

Cholera in Haiti

\section{Acknowledgements}

The authors thank the Leverhulme Trust (Grant RPG-2012-736) for their financial support of the research reported here. The authors are also grateful to the anonymous referees for their comments on an earlier version of the manuscript. 


\begin{abstract}
The current epidemic of El Tor cholera in the Caribbean republic of Haiti is one of the largest single outbreaks of the disease ever recorded. The prospects are that the epidemic will continue to present challenges to workers in public health medicine, epidemiology and allied fields in the social sciences for years to come. This article introduces geographers to the environmental context of the Haiti cholera epidemic, the principal data sources available to analyze the occurrence of the epidemic, and evidence regarding its geographical origins and dispersal during the first thirty months of the epidemic, October 2010-March 2013. Using weekly case data collated by the Haitian Ministère de la Santé Publique et de la Population (MSPP), techniques of time series analysis are used to examine inter- and intra-departmental patterns of cholera activity. Our analysis demonstrates a pronounced lag structure to the spatial development of the epidemic (Artibonite and northern departments $\Rightarrow$ Ouest and metropolitan Port-au-Prince $\Rightarrow$ southern departments). Observed variations in levels of epidemiological integration, both within and between departments, provide new perspectives on the spatio-temporal evolution of the epidemic to its March 2013 pattern.
\end{abstract}

\title{
Key words
}

Cholera, Diffusion, Epidemic, Haiti, Time series analysis 


\section{Introduction}

The ongoing epidemic of El Tor cholera in the Caribbean republic of Haiti is one of the largest recorded outbreaks of cholera in the modern era (Figure 1). Beginning with a putative introduction by Nepalese peacekeepers in mid-October 2010, the cumulative number of reported cholera cases had reached 704,371 by the week ending 19 July 2014, of which 394,896 had been hospitalized and 8,580 had died (Pan American Health Organization 2014a). More than 6 percent of the country's population of 10.32 million had been infected in this period, with a case-fatality rate for clinical cases of 1.2 percent (Pan American Health Organization 2014a, 2014b). From Haiti, the disease has spilled into the Dominican Republic, United States, Cuba and, most recently, Mexico (Centers for Disease Control and Prevention 2010e; Moore et al. 2014). The current plan of the Ministère de la Santé Publique et de la Population (MSPP) to eliminate cholera in Haiti by the year 2022 indicates that the disease will remain a problem in the country for years to come (Ministère de la Santé Publique et de la Population 2013).

\section{FIGURE 1 NEAR HERE}

This article presents a medical geographical perspective on the evolution of the Haiti cholera epidemic to its spatial pattern in March 2013. We apply analytical concepts and modelling techniques that provide intrinsically geographical insights into transmission patterns and processes that, in the context of the Haiti epidemic, have not previously been explored in the literature. Based on a systematic analysis of the records of some 600,000 clinical cases of cholera, we demonstrate that the evolution of the epidemic was underpinned by a fundamental geographical divide between the northern and southern departments of the country. This north-south divide manifested as a spatial lead-lag structure in epidemic development, with the capital department (Ouest) serving as a pivot point in the southwards spread of the disease. Importantly from the perspective of disease intervention, our analysis also identifies pronounced differences in the degree of epidemiological integration of geographical units. This information should inform the spatial planning and implementation of ongoing cholera elimination strategies in the country. 


\section{Epidemic Context}

The cholera epidemic in Haiti has spread against a backdrop of poor health, water and sanitation infrastructure. In 2008, only 12 percent of Haitians received piped treated drinking water and just 17 percent had access to adequate sanitation (Ali et al. 2011; Ceccarelli et al. 2011). The epidemic followed nine months after a moment magnitude (Mw) 7.0 earthquake on 12 January 2010 with an epicentre just $25 \mathrm{~km}$ west of the capital, Port-au-Prince. The net outflow of people from the Port-au-Prince area in consequence of the earthquake is estimated to have been 20 percent of the pre-earthquake population (Bengtsson et al. 2011). Many internally displaced persons (IDPs) were housed in temporary camps which were then flooded on 5 November 2010 when Hurricane Tomas hit the country. Despite the importance of these factors in catalysing the epidemic, public and political controversy has centred on the role of UN peacekeepers in the initial introduction of cholera (Cravioto et al. 2011).

As measured by morbidity, the Haitian epidemic is the largest reported outbreak of the disease since the nineteenth century, and it has occurred in a country with no previous recorded history of the disease. As a consequence, the disease has spread in an immunologically naïve population (Dowell and Braden 2011). The >700,000 cases that had occurred by July 2014 puts the magnitude of the epidemic on a different scale to other recent outbreaks (Ali et al. 2012). In 2010, Haiti accounted for 57 percent of the world's total cholera cases reported to the World Health Organization (WHO) and 53 percent of all cholera deaths. In 2011 the situation was little changed: 58 percent of the world's cholera cases and 37 percent of deaths reported to WHO were in Haiti (Barzilay et al. 2013). The outbreak continues, albeit at a much lower level. The weekly average for new cases in the first five months of 2014 was 291 with 1 death. This can be compared with the weekly averages of 993 cases and 8 deaths in 2013, 1,498 cases and 11 deaths in 2012, and 7,697 cases and 62 deaths in 2011 (Pan American Health Organization 2014a).

The Haitian epidemic is related to the country's poverty in several ways. First, in the absence of human and financial resources to deal with the consequences of the January 2010 earthquake, international peacekeepers were provided by the United Nations to help those displaced by the earthquake. This act appears to have introduced cholera into the country (Ali 
et al. 2011; Ceccarelli et al., 2011; Chin et al. 2011; Cravioto et al. 2011; Hendriksen et al. 2011; Mutreja et al. 2011). Second, the earthquake damage to already poor sewerage and water systems increased population vulnerability to cholera (Ali et al. 2011; Ceccarelli et al. 2011; Chery, Dodard, and Fournier 2012). Third, control of the epidemic, once it was under way, was handicapped by Haiti's weak, mostly privatized, national healthcare system which is inaccessible to much of the population (Farmer 2011). Finally, the ongoing population displacement and associated inter-departmental movements since the earthquake have maintained the nationwide spread of the disease (Bengtsson et al. 2011; Chery, Dodard, and Fournier 2012).

\section{The Study and Layout of the Article}

Medical geographers have a longstanding interest in the spatial transmission of cholera (May 1951) and a rich vein of geographical scholarship has developed in relation to the spread of the disease. In addition to atlas-based treatments of pandemic wave transmission (May 1951; Cliff, Haggett, and Smallman-Raynor 2004, 25-32), geographers have examined the spatial dimensions of nineteenth and early twentieth century cholera epidemics in, among other countries, Japan (Kuo and Fukui 2007), Russia (Patterson 1994), the United Kingdom (Cliff and Haggett 1988, 2-61) and the United States (Pyle 1969). Other geographical studies have investigated the spread of cholera in relation to past conflicts (Smallman-Raynor and Cliff 1998a, 1998b, 2004), while social constructions of the disease in the nineteenth century have also been explored (Jackson 2013). More particularly, the present study is underpinned by an ongoing geographical concern with the spatial transmission of cholera as illustrated by the recent series of modelling studies in relation to Matlab, Bangladesh (Giebultowicz et al. 2011; Emch et al. 2012).

Our examination of the Haiti cholera epidemic is framed by a broader geographical concern with the impacts and consequences of the Haiti earthquake of January 2010, including environmental health risks (Curtis et al. 2013; Widmer et al. 2014), post-disaster mobility, humanitarian logistics and aid (Sheller 2013; Versluis 2014), environmental sustainability (Abrahams 2014), cultural legacies (Cruse 2013) and representations of disaster 
vulnerability (Taylor 2013). As a contribution to this broader literature, we present a medical geographical perspective on the national spread dynamics and spatial structure of the postearthquake cholera epidemic, October 2010-March 2013. Geographers have much to contribute to an improved understanding of the spatial and temporal dimensions of the outbreak. As such, this article is intended as both an introduction and reference point for future geographical investigations of the epidemic.

The article begins with a reconstruction of the initial diffusion of the cholera epidemic from its putative origin at the United Nations Stabilization Mission in Haiti (MINUSTAH) camp complex, Centre Department, to the rest of the country in the period OctoberDecember 2010. This was the first, and the largest, of several major waves of cholera to spread through Haiti during the first thirty months of the epidemic (Figure 2). In subsequent sections of the article, we use methods of time series and coherence analysis to examine the spatial structure of this ongoing epidemic. Our results shed fresh light on the geographical evolution of the epidemic and provide important insights for the spatial elimination of cholera in Haiti.

\section{FIGURE 2 NEAR HERE}

\section{Background and Historical Context}

\section{The Haiti Earthquake (12 January 2010)}

The earthquake that struck Haiti at 16:53 hours (local time) on Tuesday 12 January 2010 was one of the most destructive in modern history (Centre for Research on the Epidemiology of Disasters 2014). With an epicentre near the town of Léogâne, approximately $25 \mathrm{~km}$ west of Port-au-Prince, the earthquake caused US\$8,000 millions of damage to the physical infrastructure of the capital city and elsewhere in the departments of Ouest, Nippes and SudEst (Figure 3A). Government officials estimated that the earthquake resulted in 230,000 immediate deaths, with an additional 300,000 people injured and some 2 million in need of temporary shelter. Among the latter, 1.5 million people settled in the many hundreds of overcrowded IDP camps that had appeared spontaneously in and around Port-au-Prince 
(Figure 3C) and, further to the west, in the communes of Léogâne, Jacmel and Petit-Goâve (Figure 1). Another 0.6 million people moved out of the immediate area of destruction to undamaged locations in the departments of Artibonite, Centre, Grande-Anse, Sud and elsewhere (Centers for Disease Control and Prevention 2010b; Tappero and Tauxe 2011) (Figures 3B and 4).

\section{FIGURE 3 NEAR HERE}

\section{FIGURE 4 NEAR HERE}

The earthquake caused severe damage to the health care infrastructure of the Ouest, Nippes and Sud-Est departments and compromised the operational capabilities of the Haitian Ministère de la Santé Publique et de la Population (MSPP) (Santa-Olalla et al. 2013). The post-earthquake health situation was compounded by the overcrowded and insanitary conditions that prevailed in the IDP camps, with many lacking potable water, toilet and bathing facilities (International Organization for Migration in Haiti 2013); see Figure 5. Emergency health monitoring of IDPs in the 3-4 months that followed the earthquake identified acute respiratory infections, watery diarrhoea, suspected malaria and fever of unknown origin as the most commonly encountered conditions. Cases of suspected typhoid, bloody diarrhoea, acute haemorrhagic fever syndrome and acute febrile illness with jaundice were counted in the hundreds, while small numbers of actual or suspected cases of diphtheria, measles, meningococcal meningitis, rabies, tetanus and whooping cough were also recorded (Centers for Disease Control and Prevention 2010a, 2010b; Polonsky et al. 2013).

\section{FIGURE 5 NEAR HERE}

While disease monitoring activities were maintained throughout the summer of 2010 , the available records suggest that cholera - actual or suspected - was absent from Haiti at this time (Centers for Disease Control and Prevention 2011). When the disease did finally arrive in October of the same year, it found a set of pre- and post-disaster circumstances that were highly conducive to its rapid transmission. Earthquake damage to the country's already poor sewage and water systems was compounded by overcrowded and insanitary living conditions 
and deficiencies in public health infrastructure to treat and prevent the disease (Gelting et al. 2013; Santa-Olalla, et al. 2013).

\section{Hurricane Tomas (5 November 2010)}

On the morning of Friday 5 November 2010, Hurricane Tomas brushed the western-most tip of Haiti and tracked north-eastwards through the Windward Passage that separates the islands of Hispaniola and Cuba. Although the hurricane did not make landfall in Haiti, heavy rains resulted in some flooding in the five southern departments (Grande-Anse, Nippes, Ouest, Sud and Sud-Est), Artibonite, Centre and Nord-Ouest; see Figure 1 for locations. To the west of Port-au-Prince, for example, IDP camps in the town of Léogâne were inundated by overflowing river water. Other communes in the vicinity of Léogâne, including Petit Goâve and Jacmel, were also reported to have been seriously affected by the storm. Elsewhere, in mountainous areas of the country, shelters were swept away by the heavy winds and roads were blocked by mudslides and rock falls. All told, media and government reports attributed 21 deaths to the hurricane (CFE-DMHA, 2010; Centre for Research on the Epidemiology of Disasters, 2014).

Although the damage caused by Hurricane Tomas was much less severe than had been anticipated, and the United Nations (UN) had scaled down the membership of its Disaster Assessment and Coordination (UNDAC) team within a few days of the event, concerns were expressed that the flooding would serve to promote the spread of the nascent cholera epidemic and other water-borne diseases (CFE-DMHA, 2010). The concerns seem to have been justified. In one of the largest IDP camps, Parc Jean-Marie Vincent near Port-auPrince, cases of cholera began to appear on 8 November (Walton and Ivers 2011) while, elsewhere in the metropolitan area of Port-au-Prince, the epidemic took a hold in the slums of Cité-Soleil (Piarroux et al. 2011). More generally, the flooding and disruption caused by Hurricane Tomas appears to have had a pronounced effect on the national epidemic curve, with a 121 percent increase in the weekly count of new cholera cases at this time (Pan American Health Organization 2014b). 


\section{Cholera}

Cholera is a potentially severe, sometimes rapidly fatal, diarrhoeal disease due to infection with the bacterium Vibrio cholerae. Transmission of the bacterium usually occurs via the ingestion of faecally contaminated water and, less commonly, food. The majority of infections with $V$. cholerae are asymptomatic. Clinical illness arises from the ability of the bacterium to produce an enterotoxin that causes the characteristic watery diarrhoea ('rice water' stools) seen in cholera patients. Approximately 80-90 percent of clinical cases are of mild or moderate severity, with the balance following a severe clinical course. In the latter cases, an incubation period of 2-5 days is usually followed by the sudden onset of diarrhoea and vomiting, giving rise to massive fluid loss and dehydration. Consequent symptoms include cramps, a reduction in body temperature and blood pressure leading to shock and, ultimately, death within a few hours or days of symptom onset. Mortality is typically witnessed in 40-60 percent of untreated cases of severe disease (Tauxe 1998; Heymann 2008).

In terms of the epidemiology of cholera, contaminated watercourses are generally regarded as a prerequisite for a large cholera outbreak in a newly infected (non-endemic) setting. As regards the social environment, cholera epidemics are commonly associated with large population clusters, overcrowding and insanitary conditions. Inadequate systems of sewage disposal (leading to faecal contamination of watercourses) and lack of alternative supplies of potable water are integral to the transmission cycle. During the 1990s, for example, extensive waterborne transmission of cholera in Latin America was linked to faulty municipal water systems, contaminated surface waters and unsafe methods of water storage in domestic settings (Heymann 2008).

Two serogroups of $V$. cholerae are associated with cholera outbreaks: O1 and O139. V. cholerae $\mathrm{O} 1$ has two biotypes (classical and El Tor) that have spread over the last two centuries as seven global pandemic events. The first six pandemics occurred in the nineteenth century and each is believed to have been associated with the classical biotype. The El Tor biotype was first identified in Indonesian pilgrims at the El Tor quarantine station, Egypt, in 1905 and is the causative agent of the current (seventh) global pandemic wave. In contrast, $V$. 
cholerae O139 was first identified in 1992 and, although it has been recognized as the cause of epidemics in several countries of South and Southeast Asia, it has yet to establish itself as a pandemic infection (Kaper, Morris and Levine 1995; Heymann 2008).

\section{The pandemic sequence of El Tor cholera}

As far as the historical record allows, cholera was wholly unknown in Haiti prior to midOctober 2010 (Jenson et al. 2011). The current epidemic of the disease is an extension of the global pandemic of $V$. cholerae serogroup O1 (biotype El Tor) that can be traced to a likely onset in the Indonesian island of Sulawesi. Epidemics of El Tor were first observed in southern Sulawesi in the 1930s and, again, in the 1940s and 1950s. Beginning in 1960-1961, outbreak activity began to extend to the north of the island and on to other parts of the Indonesian archipelago (Mukerjee 1963; Hermann 1973). From thereon, the El Tor pandemic spread to mainland Asia (1960s), Africa (1970s), Europe (1970s) and the Americas (1990s) (Barua and Greenough 1992, 132). This pandemic sequence has since been characterized by Mutreja et al. (2011) as the product of at least three independent, but overlapping, global transmission waves centred on South Asia that spread outwards in the 1960s-1980s (Wave 1), 1990s-2000s (Wave 2) and 1980s-2000s (Wave 3). The spread of each wave has been facilitated by a range of factors, including: (i) the enhanced capacity for El Tor vibrios to survive in environmental niches; (ii) the relatively mild nature of El Tor cholera and the high frequency of asymptomatic excretors; and (iii) the heightened opportunities for disease dispersal with air passenger traffic (Kaper, Morris and Levine 1995). Available evidence indicates that the Haitian outbreak is aligned with Wave 3 of the pandemic sequence (Mutreja et al. 2011).

The severity of the cholera epidemic in Haiti has been heightened by the variant nature of the epidemic strain of the El Tor biotype in the country and, in particular, its tendency to produce increased levels of enterotoxin and more severe disease outcomes (Piarroux and Faucher 2012). Moreover, the epidemic strain is also resistant to a range of antibacterial agents including co-trimoxazole, furazolidone, sulfafurazole, and streptomycin (Ceccarelli et al. 2011). 


\section{Vibrio cholerae non-O1/0139 in Haiti}

While one dominant (El Tor) cholera strain has been identified as the root cause of the Haitian outbreak, other serogroups of $V$. cholerae have contributed to the clinical picture. For example, the normally milder pathogen $V$. cholerae non-O1/O139 found in US coastal waters may have reached Haiti as a result of the 2010 earthquake, in conjunction with a hot summer, hurricane-related flooding and poor sanitation (Kupferschmidt 2012). Evidence of serotype switching has also been found. This phenomenon is commonly driven by growing herd immunity to the dominant serotype, rendering people susceptible to re-infection with a new serotype (Centers for Disease Control and Prevention 2012; Barzilay et al. 2013). Consequently, the bacteriological picture of cholera in Haiti is now more complex than early reports suggested.

\section{The First Cholera Wave: Initial Spread Reconstructions (October- December 2010)}

The first formal indication of cholera in Haiti can be traced to Tuesday 19 October 2010 when the Haitian MSPP was notified of unusually large numbers of patients from the Artibonite and Centre Departments with acute watery diarrhoea and dehydration, in some instances resulting in death (Centers for Disease Control and Prevention 2010c). These initially affected departments largely escaped earthquake damage (Figure 3A) and had become the place of refuge for many thousands of earthquake-displaced persons from the Port-au-Prince area (Figure 4). Within four days of these reports, V. cholerae serogroup O1 (serotype Ogawa, biotype El Tor) had been isolated from patients in Artibonite. From thereon, cholera spread rapidly out of the initial disease focus to reach all other departments of Haiti by the end of the year (Table 1).

\section{TABLE 1 NEAR HERE}

\section{Tracing the Source of the Epidemic}

The source of cholera in Haiti is one of the most controversial and politically sensitive aspects of the epidemic. Early hypotheses focussed on the possibility of a local origin. It was 
suggested that the epidemic resulted from the transmission of an environmental strain of $V$. cholerae to humans and was connected, in some way, to recent tectonic activity in the Gulf of Mexico and/or prevailing climatic conditions that had promoted the growth of the aetiological agent in its environmental reservoir (Cravioto et al. 2011; Piarroux et al. 2011). Toxigenic strains of $V$. cholerae $\mathrm{O} 1$ are known to be present along the Gulf Coast of the United States and cases of cholera have periodically been identified there (Ali et al. 2011) - notably in the aftermath of Hurricanes Katrina and Rita in 2005 (Centers for Disease Control and Prevention 2006). However, as evidence regarding the nature of the epidemic strain of $V$. cholerae began to mount, attention increasingly turned to the possibility of an exogenous origin and the inadvertent introduction of the cholera agent by a human host from a distant geographical source. In particular, recognition that the epidemic was underpinned by the El Tor biotype of $V$. cholerae and that the Haitian strains were closely related to variant El Tor O1 strains that were circulating in Bangladesh (Chin et al. 2011) and Nepal (Hendriksen et al. 2011), pointed to a South Asian - possibly Nepalese - source of the disease (Anonymous 2010; Hendriksen et al. 2011). Such a source was consistent with rumours that cholera had been introduced to Haiti by a battalion of Nepalese peacekeepers who were serving with the United Nations Stabilization Mission in Haiti (MINUSTAH) (Hendriksen et al. 2011).

Informed by the possibility that cholera was introduced from South Asia, separate investigations by a UN-appointed Independent Panel of Experts on the Cholera Outbreak in Haiti (Cravioto et al. 2011) and a joint French-Haitian team of epidemiologists (Piarroux et al. 2011) focussed attention on the MINUSTAH camp complex at Mirebalais, Centre Department. The location of the camp, where a new contingent of Nepalese soldiers had arrived from Kathmandu in the period 8-24 October 2010, is shown in Figure 6A. Both investigations pinpointed the camp as the likely source of the epidemic, with the adjacent Meye (or Meille) River (a tributary of the Artibonite River) having possibly been contaminated with faecal waste both directly from the camp and from a nearby septic pit that was used by the camp's local waste contractors. The inferred direction of spread of $V$. cholerae from these sources, along the Meye River for the town of Mirebalais and the Artibonite River, is shown by the vectors in Figure 6A. 


\section{FIGURE 6 NEAR HERE}

\section{Epidemic diffusion routes}

It is convenient to conceptualize the subsequent diffusion of the cholera epidemic as a fourstage process.

Stage 1 (Figure 6A): an initial focus in the town of Mirebalais;

Stage 2 (Figure 6B): rapid spread down the Artibonite River to the coastal plain;

Stage 3 (Figure 6C): diffusion out of the Artibonite basin to other parts of the country;

Stage 4 international transmission to proximal countries.

We consider each stage in turn. To assist the discussion, Table 1 is based on the reports of the MSPP and gives the number of hospital admissions in the departments of Haiti by weekly periods, October-December 2010.

Stage 1: The Mirebalais focus (Figure 6A)

Consistent with the transmission pathway in Figure 6A, retrospective investigations of hospital records have traced the two earliest patients with cholera-like symptoms to Mirebalais Government Hospital on 17-18 October. Both patients originated from the Meye area, about 150 m downstream of the MINUSTAH camp (Cravioto et al. 2011). Evidence for earlier cases is more speculative. Ivers and Walton (2012), for example, note the case of a young male from Mirebalais who developed cholera-like symptoms on 12 October. The patient had a habit of bathing in the Latem River (fed by the Meye River) and died within 24 hours of symptom onset. Shortly thereafter, two attendants who prepared his body for the funeral wake also developed cholera-like symptoms.

\section{Stage 2: Spread along the Artibonite River Valley (Figure 6B)}

From Mirebalais, the Artibonite River served as an efficient vector in the rapid carriage of $V$. cholerae downstream to the coastal plain (Figure 6B). Multiple cases of severe diarrhoea, vomiting and dehydration presented more or less simultaneously in hospitals at Deschapelles and Saint-Marc on 20 October (Cravioto et al. 2011), with an explosive spread of the disease in the Artibonite River delta area during the next two days (Piarroux et al. 2011). 
Several hydrological features contributed to the rapid spread of cholera in the Artibonite basin. The salinity gradient of the Artibonite River provides optimal environmental conditions for the proliferation of cholera vibrios. Surrounding the river, there was widespread use of river water for washing, bathing, drinking and recreation, while a number of the early cholera cases were agricultural workers who were exposed to contaminated water from the river (Centers for Disease Control and Prevention 2010c; Ali et al. 2011; Cravioto et al. 2011; Chery, Dodard, and Fournier 2012). Piarroux et al. (2011) note that, as a consequence of the interaction of irrigation and canals with human use towards the river mouth, the start of the epidemic was explosive in Lower Artibonite. Upstream, between Mirebalais and the Artibonite delta, very few cases were initially reported. While downstream and coastal plain locations were significant risk factors for the contraction of cholera, proximity to the town of Mirebelais was not (Barzilay et al. 2013).

\section{Stage 3: Diffusion from the Artibonite basin (Figure 6C)}

From 22 October, cases of cholera began to be reported in areas that lay beyond the Artibonite basin, including Port-au-Prince and several, mainly mountainous, communes that bordered the Artibonite plain. Following Piarroux et al. (2011), the resulting spread of the epidemic to the end of November 2010 is characterized in Figure 6C as a series of five temporally and spatially staggered clusters of disease activity. Along with the initial foci of disease activity in Mirebalais and the Artibonite delta area (20-28 October), these clusters included the departments of (i) Nord-Ouest (11-29 November), (ii) Ouest, including Port-auPrince (14-30 November) and (iii) Nord and Nord-Est (21-30 November). The development of these clusters is reflected in the marked increase in reported hospital admissions from Week 4 of the epidemic (Table 1). In contrast, Table 1 shows that the more southerly departments (Grande-Anse, Nippes, Sud and Sud-Est) remained relatively free of cholera at this time.

\section{Stage 4: International transmission}

The cholera epidemic did not remain confined to Haiti. By mid-November 2010, cases of cholera that were directly linked to the Haiti outbreak had been confirmed in both the 
Dominican Republic and the USA (Florida). All of the Florida cases and several in the Dominican Republic were among travellers from Haiti. Additional transmission routes into the Dominican Republic were also apparent; a number of early cases were reported among communities on the banks of the Artibonite River close to the Haitian border, with consumption of untreated river water as the most likely source of infection (Centers for Disease Control and Prevention 2010e).

\section{Summary}

By the beginning of 2011, the cumulative count of reported cholera cases in Haiti had exceeded 110,800. Of these, almost 94,800 had been hospitalized and 3,651 had died (Pan American Health Organization 2014b). As judged by hospitalized cases, Table 1 shows that the major centres of reported disease activity were Nord (23,019 cumulative cases), Ouest $(21,806)$ and Artibonite $(20,111)$ departments; all other departments had reported <10,000 hospitalized cases. This period marked the zenith of the first - and the largest - of the several waves of cholera activity that spread through Haiti in the months and years to March 2013 (Figure 2). It is to the spatial structure of this ongoing epidemic activity that we now turn.

\section{Spatial Diffusion Structures (October 2010-March 2013)}

To examine the spatial structure of the cholera epidemic in Haiti, the cholera data collated by the Haitian MSPP over a 30-calendar month period, October 2010-March 2013, are analyzed. The analysis is undertaken at two spatial levels: (i) departments $(n=10)$ and (ii) communes $(n=140)$. We begin by outlining the nature of the disease matrices that can be constructed from the cholera surveillance reports at each spatial level. These matrices are then analyzed using cross-correlation analysis (departments) and coherence analysis (communes).

\section{Cholera data}

\section{Cholera surveillance data}

Prior to the 2010 earthquake, no systematic reporting of diarrhoeal disease was undertaken in Haiti at either national or regional levels (Cravioto et al. 2011). After the earthquake, two 
disease surveillance systems were quickly established by the MSPP in conjunction with the Pan American Health Organisation (PAHO) and the US Centers for Disease Control and Prevention (CDC). These were the National Sentinel Surveillance System (NSSS) and the Internally Displaced Persons Surveillance System (IDPSS). The systems were designed to gather data and guide earthquake relief efforts. While the systems undertook surveillance for acute watery diarrhoea, they were not designed to handle an outbreak of the size of the cholera epidemic which began in October 2010. To meet this need, a cholera-specific surveillance system, the National Cholera Surveillance System (NCSS), was established by the MSPP within days of the first detection of cholera. Using a modified WHO clinical case definition for cholera ('acute watery diarrhoea, with or without vomiting'), the NCSS collects data at department and commune level (Barzilay et al. 2013). Standardized reports of hospital- and community-based cholera cases and deaths are available on a weekly basis at (i) the department level from the week ending 23 October 2010 and (ii) the commune level from the week ending 23 May 2011. All reports are accessible via the MSPP (http://www.mspp.gouv.ht) and PAHO (http://new.paho.org/hq) websites, where additional information is also available for the Dominican Republic.

There are several limitations to the cholera data collected through the NCSS and included in the published reports of the MSPP. First, the surveillance system is facility-based and coverage is partial in remote areas with limited access to health services. Second, the enumeration of community-based deaths is not performed by trained medical personnel. Anecdotal evidence suggests that community deaths due to cholera are likely to be underreported. Third, reporting completeness is sometimes sacrificed for timeliness by communes and, when necessary, antecedent data are updated during the preparation of reports. Finally, the majority of cholera cases in the NCSS are not laboratory confirmed and, inevitably, some cases of watery diarrhoea caused by pathogens other than $V$. cholerae appear in the statistics (Barzilay et al. 2013; Centers for Disease Control and Prevention 2010c, 2010d). 


\section{Cholera data matrices}

Data abstracted from the MSPP reports were used to create space-time matrices of the weekly incidence of (i) all cholera cases and (ii) hospitalized cholera cases. Matrices were built at the department level $(n=10)$ for a 127-week period (epidemic weeks ending 23 October 2010 to 23 March 2013) and at the commune level $(n=140)$ for a 98-week period (epidemic weeks ending 14 May 2011 to 23 March 2013). The matrices included records for a total 593,340 cholera cases, of which 360,748 were hospitalized. The pie charts in Figure 1 show the distribution of these cases by department. Associated epidemic curves, aggregated to the national level, are plotted on a weekly basis in Figures 2A and D.

\section{Methods and Results, I: Department-Level Analysis}

In this section, we examine the manner in which departments have interacted with each other as the cholera epidemic has diffused through them. For this purpose, we follow SmallmanRaynor and Cliff (1998b, 1999) in adopting one powerful technique for characterising such spatial interactions in an epidemiological framework, namely cross-correlation analysis. Full details of the statistical approach are provided in Appendix 1 but, in essence, the weekly counts of cholera incidence (new cholera cases and new cholera admissions to hospital) for each of the 10 departments in the interval to March 2013 were treated as a time series. Crosscorrelation analysis then proceeds by computing the degree of association $\left(r_{k}\right)$ between any two cholera time series which are $k$ time lags (here, weeks) apart. The time lag at which the maximum association occurs is taken as the lead or lag of the cholera epidemic in one department with respect to another.

\section{Results}

The principal results of the cross-correlation analysis are summarized in Table 2 and Figure 7A. Table 2 gives the average value of the maximum association $\left(\bar{r}_{k}\right)$ and the average weekly lead (positive values of $\bar{k}$ ) or lag (negative values of $\bar{k}$ ) of the named department with all other departments. To assist in the interpretation of the table, the maps in Figure 7A link each department to the department with which it shared the highest association. The information is 
shown for all cholera cases (maps i and ii) and hospitalized cholera cases (maps iii and iv). Additional facets of Figure 7A are summarized in the figure caption and Appendix 1.

\section{TABLE 2 NEAR HERE}

FIGURE 7 NEAR HERE

Four interlinked features of the spatial structure of the cholera epidemic in Haiti emerge from Table 2 and Figure 7. These are: (1) the tendency for Artibonite and the northern departments to lead the development of the epidemic; (2) the tendency for the southern departments to lag the development of the epidemic; (3) the implied north-south divide in epidemic transmission that follows from features (1) and (2); and (4) the role of hierarchical 'leaps' in the spatial transmission structure. We consider each feature in turn.

(1) Northern department leads. Table 2 shows positive values of $\bar{k}$ between northern departments (with the exception of Nord-Est) and other departments, while southern departments have negative or close to zero $\bar{k}$ with other departments. This implies northern departments led the development of the epidemic. Artibonite has both the largest average association with all other departments and the longest lead. This is consistent with the likely role of Artibonite as an index location for the spread of cholera to adjacent (Nord, NordOuest) and other departments. The lead-lag structure for hospitalized cholera cases in maps (iii) and (iv) of Figure 7A also reflects this.

(2) Southern department lags. In Figure 7A, the southern-most departments (Grand-Anse, Nippes, Sud and Sud-Est) are characterized by generally weak associations with the northern departments, consistent with their position in the lead (northern departments)-lag (other departments) structure of epidemic development. Two further features also emerge from Figure 7A: (a) the relatively high level of local epidemiological integration of the southernmost departments implied by the large numbers of associations with each other; and, in turn, (b) their connections with the epidemic in Port-au-Prince and Ouest. This is consistent with an epidemic which, in the southern-most districts, has been driven by the developments in the metropolitan area. 
(3) A north-south divide. The evidence in Table 2 and Figure 7A suggests a north-south split dividing Haiti into two diffusion islands, with the south firing later than the north. There appears to be a watershed in the spread of cholera along the Chaîne des Matheux hills which run northwest-southeast between the Artibonite River and Port-au-Prince (see Figure 1 for location). Taking Artibonite Department as the reference series, its average lag with the set of southern districts (Grande Anse, Nippes, Ouest, Sud and Sud-Est) in Table 2 implies that this watershed was crossed after 4-6 weeks.

(4) Hierarchical leaps. Apparent long-distance 'leaps' of cholera between northern and southern departments are implied by the prominent bonds in Figure 7A, including several that involve the index department (Artibonite) with the southern-most departments of Sud (map iii) and Grande-Anse (map iv). Similar associations are noted for Nord-Est with Sud-Est (map i), Grand-Anse (map iii) and Nippes (map iii), and for Centre with Nippes (map iv). Caution, however, should be exercised in the interpretation of these findings. While it is tempting to assume that they are indicative of long-distance transmission episodes, possibly associated with the population movements engendered by the earthquake and the epidemic, some of the associations may reflect the confounding effects of delayed epidemic onset in peripheral departments of the country.

A schematic model of the diffusion process implied by Table 2 and Figure 7A is proposed in Figure 7B.

\section{Methods and Results, II: Commune-Level Analysis}

To examine the geographical structure of cholera activity at the commune level, we draw upon the concept of geographical coherence in epidemiological investigations (Cliff et al. 1992). As described in Appendix 2, the weekly time series of reported cholera cases in each of the communes of Haiti can be correlated with each other to see how far the temporal behaviour of one geographical unit corresponds with that of another. Pairs of communes that have very similar cholera time series can be described as having strong geographical coherence; those with dissimilar series have weak geographical coherence. For a given 
department, we take the average correlation $(\bar{r})$ between all pairs of constituent communes as a measure of internal coherence for that department.

\section{Results}

Figure 8 summarizes the results of the coherence analysis for all cholera cases (map A) and hospitalized cases (map B). Both maps identify the northern departments of Artibonite and Nord ( $\bar{r} \geq 0.4)$ and the southern departments of Grande-Anse and Sud ( $\bar{r} \geq 0.3)$ as having the highest levels of internal coherence, indicative of groups of communes that display very similar patterns of reported disease activity. Lower levels of coherence are recorded for all other departments, although modest variations in the categorized values of $\bar{r}$ are evident between the two maps.

\section{FIGURE 8 NEAR HERE}

The relatively high levels of internal coherence identified for Artibonite, Nord, Grand-Anse and Sud are consistent with the operation of these departments as integrated epidemiological systems. Here, the primary vectors of $V$. cholerae (human carriers and watercourses) have resulted in an efficient epidemiological linkage of the constituent communes to yield very similar patterns of disease activity in time. In contrast, the relatively low levels of internal coherence identified for some other departments, including the major epidemic focus of Ouest, are consistent with the operation of weakly integrated epidemiological systems. In these systems, the primary vectors of $V$. cholerae have - for social, physical, technological or other reasons - been limited in their capacity to link efficiently all the constituent communes so that the geographical extent or rate of disease transmission has been correspondingly curtailed. By way of a simple illustration of the phenomenon, the comparatively low coherence for Nord-Ouest may reflect (i) the relative isolation of more remote communes from the primary road network and (ii) the role of the sea as a physical barrier in the transmission of cholera from the mainland communes to the island commune of La Tortue (Figure 1). It is reasonable to assume that the physical geography of Haiti (Figure 7C) has played a more general role in the observed levels of epidemiological 
coherence, with physical barriers serving to delay or halt the spread of cholera to the more remote communes of some departments.

\section{Conclusion}

The current epidemic of cholera in Haiti is in urgent need of investigations that will lead to effective interventions for the control and, ultimately, the elimination of the disease. An improved understanding of the spatial and temporal dimensions of the epidemic is one approach towards achieving this goal (Bertuzzo et al. 2011; Chao, Halloran, and Longini 2011; Andrews and Basu 2011; Mukandavire, Smith, and Morris 2013). We suggest that geographers are ideally positioned to contribute to this pressing area of health research. As a reference point for future investigations, the present article has attempted to introduce geographers to aspects of the origin and course of the epidemic and, importantly, to the substantial body of associated literature that has accrued since October 2010.

Our own analysis of the MSPP's morbidity data has added to a geographical understanding of the cholera epidemic in terms of both (i) the spatial macrostructure of epidemic development (Figure 7 and Table 2) and (ii) the differential levels of epidemiological integration of the administrative units of Haiti (Figure 8). In an earlier study, Tuite et al. (2011) used a compartmental modelling strategy with a gravity model component to simulate the spatial transmission of cholera in the initial stages of the Haiti epidemic. Their analysis identified a clear tendency for the 'gravitational effects' of population size and geographical proximity to reproduce the inter-department dynamics of epidemic transmission. While our use of cross-correlation analysis has underscored the contagious and hierarchical transmission elements implied by the gravity modelling approach of Tuite and colleagues (Figure 7), we have further demonstrated that the evolution of the epidemic to its pattern in March 2013 was underpinned by a fundamental geographical divide between the northern and southern departments of the country. This north-south divide manifested as a spatial lead-lag structure (Artibonite and northern departments $\Rightarrow$ Ouest $\Rightarrow$ southern departments), with the capital department (Ouest) serving as a pivot point in the southwards spread of the epidemic (Figure 7B). 
The National Plan of Action for the Elimination of Cholera in Haiti 2013-2022 foresees a 10-year project to eliminate cholera from Haiti and the Dominican Republic (Ministère de la Santé Publique et de la Population 2013). Funds will be used to improve the supply of potable water and sanitation infrastructure, thus breaking cholera's faecal-oral transmission route. As control strategies move towards the elimination of the disease in localized areas of the country, the possibility of disease re-importations into cholera-free localities demands knowledge of those spatial channels through which such re-importations may occur. In this context, the results of our coherence analysis have pointed to the existence of pronounced differences in the degree of epidemiological integration of departments (Figure 8). An understanding of those factors that have governed these differential levels of epidemiological integration, and which serve to promote or impede the efficient spatial transmission of $V$. cholerae from one commune to another in a given department, may serve to guide the spatial planning and implementation of future intervention strategies (Ministère de la Santé Publique et de la Population 2013).

The MSPP's plan to eliminate cholera from Haiti by the year 2022 indicates that the disease will remain a problem in the country in the medium-term. The elimination programme incorporates a strategy in which health services will be rolled out so that everyone lives within a "reasonable distance" of a health post (Ministère de la Santé Publique et de la Population 2013,4). If successful, this plan will equip Haitians with much needed and long-awaited basic infrastructure which will have health and social benefits that go beyond the control of cholera. Geographers have an important role to play in the promotion of this broader development process. 


\section{Appendix 1: Cross Correlation Analysis (Table 2, Figure 7)}

The theory behind cross-correlation analysis is discussed in Box, Jenkins, and Reinsel (2008). For the $t=127$ weeks to March 2013, the weekly counts of cholera incidence (new cholera cases and new cholera admissions to hospital) for each of the $n=10$ departments were treated as a time series. Cross-correlation analysis then proceeds by computing the correlation coefficient, $r_{k}$, between any two time series which are $k$ time lags (here, weeks) apart. The value of $k$ at which the maximum correlation occurs is conventionally taken as the lead or lag of one time series with respect to another. Let $x_{i t}$ denote the cholera incidence for department $i$ in week $t$ and $x_{j t}$ the corresponding value for department $j$. Then the cross-correlation at lag $k, r_{k}$, is given by

$$
r_{k}=\operatorname{corr}\left[x_{i t}, x_{j, t+k}\right]=\sum\left[\left(x_{i t}-\bar{x}_{i}\right)\left(x_{j, t+k}-\bar{x}_{j}\right)\right] /\left[\sum\left(x_{i}-\bar{x}_{i}\right)^{2} \sum\left(x_{j}-\bar{x}_{j}\right)^{2}\right]^{1 / 2},
$$

where $\bar{x}_{i}$ and $\bar{x}_{j}$ are the means of the time series. In the notation of equation A1, the $\left\{x_{i t}\right\}$ are termed the reference series and the $\left\{x_{j t}\right\}$ the comparison series. If $k=0$, the reference and the comparison series are said to be in phase; $+k(k>0)$ signifies that the reference series leads the comparison series, and $-k(k<0)$ that the reference series lags the comparison series. Finally, a plot of the correlation coefficient, $r_{k}$, against the lag $k$ yields the cross-correlation function $(\mathrm{CCF})$.

The weekly series of cholera incidence in each of the ten departments were systematically treated as the reference series in equation A1 against which the remaining nine series were compared, thereby yielding a total of $(10 \times 9=) 90 \mathrm{CCFs}$ for (i) all cholera cases and (ii) hospitalized cholera cases. A basic assumption of cross-correlation analysis is that the series to be analyzed are time-stationary (Chatfield 2003). Accordingly, prior to analysis, all series were detrended using techniques of first differencing (Gottman 1981). In the present article, we report the results of the cross-correlation analysis as performed for both raw and detrended data.

The principal results of the cross-correlation analysis are summarized in Table 2 . The table gives the average value of the maximum correlation $\left(\bar{r}_{k}\right)$ and the average lead/lag in 
weeks $(\bar{k})$ of a given department (reference series; $x_{i t}$ in equation A1) with all other departments (comparison series; $x_{j t}$ in equation A1) over lags $-12 \leq k \leq 12$. Here, $+\bar{k}$ indicates that, on average, the reference department leads the comparison departments by $k$ weeks. Conversely, $-\bar{k}$ indicates, that on average, the reference department lags the comparison departments by $k$ weeks. The maps in Figure 7A link each department to the department with which it shared the highest value of $r_{k}$ at lags $0 \leq \mathrm{k} \leq 12$ (i.e. the pattern of leads). Vector line widths define the strengths of the correlations. In-phase (reciprocal links; $k=0$ ) and out-of-phase (unidirectional links; $k \neq 0$ ) are illustrated. Vector line colours define the lag, $k$. 


\section{Appendix 2: Coherence Analysis (Figure 8)}

The $n=140$ communes of Haiti were partitioned according to the country's ten administrative departments. For a given department, Pearson's product-moment correlation coefficient $(r)$ was then used to compute the degree of correlation between the weekly time series of reported cholera cases in one commune and all other communes. The average correlation, $\bar{r}$, across the set of commune pairs was taken as a measure of the extent to which the constituent communes of a given department operated as an integrated epidemiological system. We refer to this as internal coherence. As for the cross-correlation analysis, coherence analysis was performed using raw and first differenced time series of (i) all cholera cases and (ii) hospitalized cholera cases in the period May 2011-March 2013. Because analysis of the raw and first differenced time series yielded similar results, we limit our consideration in Figure 8 to the findings for the raw data. 


\section{References}

Abrahams, D. 2014. The barriers to environmental sustainability in post-disaster settings: A case study of transitional shelter implementation in Haiti. Disasters 38 (S1): S25-49.

Ali, A., Y. Chen, J. A. Johnson, E. Redden, Y. Mayette, M. H. Rashid, O. C. Stine, and J. G. Morris Jr. 2011. Recent clonal origin of cholera in Haiti. Emerging Infectious Diseases 17 (4): 699-701.

Ali, M., A. L. Lopez, Y. A. You, Y. E. Kim, B. Sah, B. Maskery, and J. Clemens. 2012. The global burden of cholera. Bulletin of the World Health Organization 90 (3): 209-18A.

Andrews, J. R., and S. Basu. 2011. Transmission dynamics and control of cholera in Haiti: An epidemic model. The Lancet 377 (9773): 1248-55.

Anonymous. 2010. As cholera returns to Haiti, blame is unhelpful. The Lancet Infectious Diseases 10 (12): 813.

Barua, D., and W. B. Greenough. 1992. Cholera. New York: Plenum.

Barzilay, E. J., N. Schaad, R. Magloire, K. S. Mung, J. Boncy, G. A. Dahourou, E. D. Mintz, M. W. Steenland, J. F. Vertefeuille, and J. W. Tappero. 2013. Cholera surveillance during the Haiti epidemic - the first 2 years. New England Journal of Medicine 368 (7): 599-609.

Bengtsson, L., X. Lu, A. Thorson, R. Garfield, and J. von Schreeb. 2011. Improved response to disasters and outbreaks by tracking population movements with mobile phone network data: A post-earthquake geospatial study in Haiti. PLoS Medicine, 8(8):e1001083. doi: 10.1371/journal.pmed.1001083.

Bertuzzo, E., L. Mari, L. Righetto, M. Gatto, R. Casagrandi, M. Blokesch, I. RodriguezIturbe, and A. Rinaldo. 2011. Prediction of the spatial evolution and effects of control measures for the unfolding Haiti cholera outbreak. Geophysical Research Letters 38, L06403. doi: 10.1029/2011GL046823. 
Box, G. E. P., G. M. Jenkins, and G. C. Reinsel 2008. Time series analysis: Forecasting and control. Hoboken, NJ: John Wiley.

Ceccarelli, D., M. Spagnoletti, P. Cappuccinelli, V. Burrus, and M. M. Colombo. 2011. Origin of Vibrio cholerae in Haiti. The Lancet Infectious Diseases 11 (4): 262.

Centers for Disease Control and Prevention. 2006. Two cases of toxigenic Vibrio cholerae O1 infection after Hurricanes Katrina and Rita - Louisiana, October 2005. Morbidity and Mortality Weekly Report 55 (2): 31-2.

—. 2010a. Launching a national surveillance system after an earthquake - Haiti, 2010. Morbidity and Mortality Weekly Report 59 (30): 933-8.

—. 2010b. Rapid establishment of an internally displaced persons disease surveillance system after an earthquake - Haiti, 2010. Morbidity and Mortality Weekly Report 59 (30): 939-45.

—. 2010c. Update: Cholera outbreak - Haiti, 2010. Morbidity and Mortality Weekly Report 59 (45): 1473-9.

—. 2010d. Update: Outbreak of cholera - Haiti, 2010. Morbidity and Mortality Weekly Report 59 (48): 1586-90.

—. 2010e. Update on cholera - Haiti, Dominican Republic and Florida, 2010. Morbidity and Mortality Weekly Report 59 (50): 1637-41.

- 2011. Cholera in Haiti: One year later. Atlanta: CDC. http://www.cdc.gov/haiticholera/haiti_cholera.htm (last accessed 27 November 2014).

—. 2012. Identification of Vibrio cholerae serogroup O1, serotype Inaba, biotype El Tor strain - Haiti, March 2012. Morbidity and Mortality Weekly Report 61 (17): 309.

Centre for Research on the Epidemiology of Disasters. 2014. EM-DAT: The International Disaster Database. Brussels: Université Catholique de Louvain. http://www.emdat.be (last accessed 27 November 2014). 
CFE-DMHA. 2010. Haiti: Hurricane Tomas update. Tuesday November 9, 2010. Hawaii: Center for Excellence in Disaster Management and Humanitarian Assistance. http://reliefweb.int/report/haiti/haiti-hurricane-tomas-update-monday-november-92010 (last accessed 27 November 2014).

Chao, D. L., M. E. Halloran, and I. M. Longini Jr. 2011. Vaccination strategies for epidemic cholera in Haiti with implications for the developing world. Proceedings of the National Academy of Sciences, USA 108 (17): 7081-5.

Chatfield C. 2003. The analysis of time series: An introduction (sixth edition). London: Chapman and Hall.

Chery, M., M. Dodard, and A. Fournier. 2012. Cholera in Haiti's Artibonite Valley. Revista Panamericana de Salud Pública 31 (4): 349-50.

Chin C. S., J. Sorenson, J. B. Harris, W. P. Robins, R. C. Charles, R. R. Jean-Charles, J. Bullard, D. R. Webster, A. Kasarskis, P. Peluso, E. E. Paxinos, Y. Yamaichi, S. B. Calderwood, J. J. Mekalanos, E. E. Schadt, and M. K. Waldor. 2011. The origin of the Haitian cholera outbreak strain. New England Journal of Medicine 364 (1): 33-42.

Cliff, A. D., and P. Haggett. 1988. Atlas of disease distributions: Analytic approaches to epidemiological data. Oxford: Blackwell Reference.

Cliff, A. D., P. Haggett, and M. Smallman-Raynor. 2004. World atlas of epidemic diseases. London: Arnold.

Cliff A. D., P. Haggett, D. F. Stroup, and E. Cheney. 1992. The changing geographical coherence of measles morbidity in the United States, 1962-88. Statistics in Medicine 11 (11): 1409-24.

Cravioto, A., C. F. Lanata, D. S. Lantagne, and G. B. Nair. 2011. Final Report of the Independent Panel of Experts on the Cholera Outbreak in Haiti. New York: United Nations http://www.un.org/News/dh/infocus/haiti/UN-cholera-report-final.pdf (last accessed 27 November 2014). 
Cruse, M. 2013. Place in Haitian literature since the 2010 earthquake. Geographical Review 103 (4): 469-83.

Curtis, A., J. K. Blackburn, J. M. Widmer, and J.G. Morris, Jr. 2013. A ubiquitous method for street scale spatial data collection and analysis in challenging urban environments: Mapping health risks using spatial video in Haiti. International Journal of Health Geographics, 12:21. doi: 10.1186/1476-072X-12-21.

Dowell, S. F., and C. R. Braden. 2011. Implications of the introduction of cholera to Haiti. Emerging Infectious Diseases 17 (7): 1299-300.

Emch, M., E. D. Root, S. Giebultowicz, M. Ali, C. Perez-Heydrich, and M. Yunus. 2012. Integration of spatial and social network analysis in disease transmission studies. Annals of the Association of American Geographers 105 (5): 1004-15.

Farmer, P. 2011. Haiti after the earthquake. New York: Public Affairs.

Gelting, R., K. Bliss, M. Patrick, G. Lockhart, and T. Handzel. 2013. Water, sanitation and hygiene in Haiti: Past, present, and future. American Journal of Tropical Medicine and Hygiene 89 (4): 665-70.

Giebultowicz, S., M. Ali, M. Yunus, and M. Emch. 2011. A comparison of spatial and social clustering of cholera in Matlab, Bangladesh. Health and Place 17 (2): 490-7.

Gottman, J. M. 1981. Time series analysis: A comprehensive introduction for social scientists. Cambridge, UK: Cambridge University Press.

Hendriksen, R. S., L. B. Price, J. M. Schupp, J. D. Gillece, R. S. Kaas, D. M. Engelthaler, V. Bortolaia, T. Pearson, A. E. Waters, B. P. Upadhyay, S. D. Shrestha, S. Adhikari, G. Shakya, P. S. Keim, and F. M. Aarestrup. 2011. Population genetics of Vibrio cholerae from Nepal in 2010: evidence on the origin of the Haitian outbreak. mBio 2 (4):e00157-11. doi: 10.1128/mBio.00157-11.

Hermann, W. 1973. Die El-Tor-cholera-pandemie 1961 bis 1968 (The El Tor cholera pandemic, 1961 to 1968). Leipzig: Johann Ambrosius Barth. 
Heymann, D. L. 2008. Control of communicable diseases manual (nineteenth edition). Washington, DC: American Public Health Association.

International Organization for Migration in Haiti. 2013. Displacement Tracking Matrix V2.0 Update. 31 March 2013. Port-au-Prince: Haiti Camp Coordination Management Cluster.

Ivers, L. C., and D. A. Walton. 2012. The "first" case of cholera in Haiti: Lessons for global health. American Journal of Tropical Medicine and Hygiene 86 (1): 36-8.

Jackson, P. S. B. 2013. Fearing future epidemics: The cholera crisis of 1892. Cultural Geographies 20 (1): 43-65.

Jenson, D., V. Szabo, and the Duke FHI Haiti Humanities Laboratory Student Research Team. 2011. Cholera in Haiti and other Caribbean regions, 19th century. Emerging Infectious Diseases 17 (11): 2130-5.

Kaper, J. B., J. G. Morris Jr., and M. M. Levine. 1995. Cholera. Clinical Microbiology Reviews 8 (1): 48-86.

Kuo, C.-L., and H. Fukui. 2007. Geographical structures and the cholera epidemic in modern Japan: Fukushima prefecture in 1882 and 1895. International Journal of Health Geographics, 6:25 doi:10.1186/1476-072X-6-25.

Kupferschmidt, K. 2012. Infectious diseases. Second bacterium theory stirs Haiti's cholera controversy. Science 336 (6088): 1493.

May, J. M. 1951. Map of the World distribution of cholera. Geographical Review 41 (2): $272-3$

Ministère de la Santé Publique et de la Population. 2013. National plan for the elimination of cholera in Haiti. Port-au-Prince: MSPP.

Moore S. M., K. L. Shannon, C. E. Zelaya, A. S. Azman, and J. Lessler. 2014. Epidemic risk from cholera introductions into Mexico. PLoS Currents 6. doi: 10.1371/currents.outbreaks.c04478c7fbd9854ef6ba923cc81eb799. 
Mukandavire, Z., D. L. Smith, and J. G. Morris, Jr. 2013. Cholera in Haiti: Reproductive numbers and vaccination coverage estimates. Scientific Reports 3:997. doi: 10.1038/srep00997.

Mukerjee, S. 1963. Problems of cholera (El Tor). American Journal of Tropical Medicine and Hygiene 12 (3): 388-92.

Mutreja, A., D. W. Kim, N. R. Thomson, T. R. Connor, J. H. Lee, S. Kariuki, N. J. Croucher, S. Y. Choi, S. R. Harris, M. Lebens, S. K. Niyogi, E. J. Kim, T. Ramamurthy, J. Chun, J. L. Wood, J. D. Clemens, C. Czerkinsky, G. B. Nair, J. Holmgren, J. Parkhill, and G. Dougan. 2011. Evidence for several waves of global transmission in the seventh cholera pandemic. Nature 477 (7365): 462-5.

Pan American Health Organization. 2014a. Epidemiological update: Cholera. 27 June 2014. Washington, DC: PAHO. http://www.paho.org/hq/index.php?option=com d ocman\&task=doc view\&gid=25978\&Itemid (last accessed 27 November 2014).

—. 2014b. Atlas of cholera outbreak in La Hispaniola, 2010-2014. Washington, DC: PAHO. http://new.paho.org/hq/images/Atlas_IHR/CholeraHispaniola/atlas.html (last accessed 27 November 2014).

Patterson, K. D. 1994. Cholera diffusion in Russia, 1823-1923. Social Science and Medicine 38 (9): 1171-91.

Piarroux, R., R. Barrais, B. Faucher, R. Haus, M. Piarroux, J. Gaudart, R. Magloire, and D. Raoult. 2011. Understanding the cholera epidemic, Haiti. Emerging Infectious Diseases 17 (7): 1161-8.

Piarroux, R., and B. Faucher. 2012. Cholera epidemics in 2010: Respective roles of environment, strain changes, and human-driven dissemination. Clinical Microbiology and Infection 18 (3): 231-8.

Polonsky, J., F. Luquero, G. Francois, C. Rousseau, G. Caleo, I. Ciglenecki, C. Delacre, M. R. Siddiqui, M. Terzian, L. Verhenne, K. Porten, and F. Checchi. 2013. Public health surveillance after the 2010 Haiti earthquake: The experience of Médecins Sans 
Frontières. PLOS Currents: Disasters. $\quad$ p. ecurrents.dis.6aec18e84816c055b8c2a06456811c7a.

Pyle, G. F. (1969). Diffusion of cholera in the United States. Geographical Analysis 1 (1): $59-75$.

Santa-Olalla, P., M. Gayer, R. Magloire, R. Barrais, M. Valenciano, C. Aramburu, J. L. Poncelet, J. C. Gustavo Alonso, D. Van Alphen, F. Heuschen, R. Andraghetti, R. Lee, P. Drury, and S. Aldighieri. 2013. Implementation of an alert and response system in Haiti during the early stage of the response to the cholera epidemic. American Journal of Tropical Medicine and Hygiene 89 (4): 688-97.

Sheller, M. 2013. The islanding effect: Post-disaster mobility systems and humanitarian logistics in Haiti. Cultural Geographies 20 (2): 185-204.

Smallman-Raynor, M., and A. D. Cliff. 1998a. The Philippines insurrection and the 1902-4 cholera epidemic: Part I - epidemiological diffusion processes in war. Journal of Historical Geography 24 (1): 69-89.

—. 1998b. The Philippines insurrection and the 1902-4 cholera epidemic: Part II - diffusion patterns in war and peace. Journal of Historical Geography 24 (2): 188-210.

—. 1999. The spatial dynamics of epidemics in war and peace: Cuba and the insurrection against Spain, 1895-98. Transactions of the Institute of British Geographers, New Series 24 (3): 331-52.

- 2004. The geographical spread of cholera in the Crimean War: Epidemic transmission in the camp systems of the British Army of the East, 1854-55. Journal of Historical Geography 30 (1): 32-69.

Tappero, J. W., and R. V. Tauxe. 2011. Lessons learned during public health response to cholera epidemic in Haiti and the Dominican Republic. Emerging Infectious Diseases 17 (11): 2087-93. 
Tauxe, R. V. 1998. Cholera. In Bacterial infections of humans: Epidemiology and control (third edition), eds. A. S. Evans and P. S. Brachman, 223-42. New York: Plenum Medical Book Company.

Taylor, M. 2013. (Re)presenting disaster vulnerability in New Zealand school geography. New Zealand Geographer 69 (2): 158-66.

Tuite, A. R., J. Tien, M. Eisenberg, D. J. Earn, J. Ma, and D. N. Fisman. 2011. Cholera epidemic in Haiti, 2010: Using a transmission model to explain spatial spread of disease and identify optimal control interventions. Annals of Internal Medicine 154 (9): 593-601

United States Agency for International Development. 2010. Earthquake-affected areas and population movement in Haiti and USG humanitarian assistance to Haiti for the earthquake (as of 12 Sep 2010). Washington, DC: USAID. http://reliefweb.int/map/haiti/earthquake-affected-areas-and-population-movementhaiti-and-usg-humanitarian-assistance-0 (last accessed 27 November 2014).

Versluis A. 2014. Formal and informal material aid following the 2010 Haiti earthquake as reported by camp dwellers. Disasters 38 (1): S94-109.

Walton, D. A., and L. C. Ivers. 2011. Responding to cholera in post-earthquake Haiti. New England Journal of Medicine 364 (1): 3-5.

Widmer, J. M., T. A. Weppelmann, M. T. Alam, B. D. Morrissey, E. Redden, M. H. Rashid, U. Diamond, A. Ali, M. B. De Rochars, J. K. Blackburn, J. A. Johnson, and J. G. Morris, Jr. 2014. Water-related infrastructure in a region of post-earthquake Haiti: High levels of fecal contamination and need for ongoing monitoring. American Journal of Tropical Medicine and Hygiene 91 (4): 790-7. 
Annals of the Association of American Geographers, forthcoming (accepted 26 January 2015)

Table 1. Hospitalized cases of cholera in the departments of Haiti, October 2010-January 2011.

\begin{tabular}{|c|c|c|c|c|c|c|}
\hline Department & $\begin{array}{c}\text { Week } 1 \\
\text { (17-23 Oct.) }\end{array}$ & $\begin{array}{c}\text { Week } 2 \\
\text { (24-30 Oct.) }\end{array}$ & $\begin{array}{c}\text { Week } 3 \\
\text { (31 Oct. }-6 \text { Nov.) }\end{array}$ & $\begin{array}{l}\text { Weeks 4-6 } \\
\text { (7-27 Nov.) }\end{array}$ & $\begin{array}{c}\text { Weeks } 7-11 \\
\text { (28 Nov.-1 Jan.) }\end{array}$ & Total \\
\hline Artibonite & 2,774 & 2,153 & 1,496 & 8,628 & 5,060 & 20,111 \\
\hline Centre & 0 & 380 & 243 & 1,473 & 3,352 & 5,448 \\
\hline Grande-Anse & 0 & 0 & 0 & 42 & 7,112 & 7,154 \\
\hline Nippes & 0 & 0 & 0 & 12 & 943 & 955 \\
\hline Nord & 6 & 114 & 284 & 6,370 & 16,245 & 23,019 \\
\hline Nord-Est & 0 & 0 & 0 & 202 & 4,075 & 4,277 \\
\hline Nord-Ouest & 0 & 141 & 324 & 3,588 & 4,079 & 8,132 \\
\hline Ouest & 88 & 135 & 0 & 5,537 & 16,046 & 21,806 \\
\hline Sud & 0 & 0 & 0 & 199 & 2,534 & 2,733 \\
\hline Sud-Est & 0 & 0 & 0 & 29 & 1,133 & 1,162 \\
\hline Total & 2,868 & 2,923 & 2,347 & 26,080 & 60,579 & 94,797 \\
\hline
\end{tabular}

Source: data from Pan American Health Organization (2014b) 
Table 2. Summary statistics of CCF analysis

\begin{tabular}{|c|c|c|c|c|}
\hline \multirow[b]{2}{*}{ Reference } & \multicolumn{2}{|c|}{$\begin{array}{l}\text { Average maximum } \\
\text { association }\left(\bar{r}_{k}\right)\end{array}$} & \multicolumn{2}{|c|}{$\begin{array}{l}\text { Average lag }(\bar{k}) \\
\quad(\text { weeks })^{1}\end{array}$} \\
\hline & All cases & Hospital cases & All cases & Hospital cases \\
\hline \multicolumn{5}{|c|}{ Northern departments } \\
\hline Artibonite & 0.57 & 0.62 & 3.11 & 5.44 \\
\hline Centre & 0.30 & 0.28 & 2.33 & 1.00 \\
\hline Nord & 0.43 & 0.61 & 2.00 & 1.00 \\
\hline Nord-Est & 0.45 & 0.63 & -2.11 & -1.89 \\
\hline Nord-Ouest & 0.47 & 0.57 & 1.22 & 3.11 \\
\hline \multicolumn{5}{|c|}{ Southern departments } \\
\hline Grande-Anse & 0.52 & 0.58 & 0.56 & -1.00 \\
\hline Nippes & 0.50 & 0.61 & -2.00 & -2.11 \\
\hline Ouest & 0.47 & 0.48 & 0.00 & -0.78 \\
\hline Sud & 0.53 & 0.58 & -5.67 & -3.11 \\
\hline Sud-Est & 0.52 & 0.54 & -0.33 & -0.89 \\
\hline \multicolumn{5}{|c|}{ Department means } \\
\hline North & 0.44 & 0.54 & 1.31 & 1.73 \\
\hline South & 0.51 & 0.56 & -1.49 & -1.58 \\
\hline
\end{tabular}

Notes: ${ }^{1}$ Positive values of $\bar{k}$ indicate that, on average, the reference department leads the other departments by $k$ weeks. Conversely, negative values of $\bar{k}$ indicate that, on average, the reference department lags the other departments by $k$ weeks. 


\section{Figure captions}

Figure 1. Location map of Haiti. The map shows the major towns, departments, communes and rivers referred to in the text. Haiti is divided into 10 departments which, in turn, are subdivided into communes. For each department, the pie charts show the cumulative number of reported cholera cases and the proportion of cases hospitalized in the 30-month interval to be analyzed in the present article (October 2010-March 2013).

Figure 2. Weekly time series of cholera cases in Haiti, October 2010-March 2013. The upper graphs relate to all cholera cases (community and hospital) and plot, as the grey bar charts, the count (graph A) and rate per 100,000 population (graph B) of newly reported cases in each week of the epidemic. The lower graphs plot the weekly rate of cholera fatalities per 100 cases (graph C) and the number of cases that were newly hospitalized each week (graph D). From an onset in mid-October, graphs (A), (B) and (D) depict three distinct waves of disease activity in Haiti. The first wave peaked in December 2010, some 10 weeks after the first cholera cases were recognized. A second wave peaked in June 2011, and a third in November 2011. Thereafter, following a lull in recorded disease activity in January-March 2012, a pronounced spike of cholera activity was seen in June 2012. The black bar charts on each graph plot the corresponding information for the neighbouring country of the Dominican Republic. Source: data from Pan American Health Organization (2014b).

Figure 3. The 2010 Haiti earthquake. The epicentre of the magnitude 7.0 earthquake that struck Haiti on Tuesday 12 January 2010 was near the town of Léogâne, Ouest Department, approximately $25 \mathrm{~km}$ west of Port-au-Prince; see Figure 1 for location. (A) Map of earthquake intensity and population exposed. (B) Estimated percentage change in the population of Port-au-Prince, December 2009-June 2010, relative to the population on 12 January 2010. The principal outward movements as a consequence of the earthquake are depicted using vectors in Figure 4. (C) Density of internally displaced persons (IDPs) and 
location of IDP camps in Port-au-Prince and adjacent earthquake-affected communes as of March 2010. Sources: (A) redrawn from the United States Agency for International Development (2010); (B) redrawn from Bengtsson et al. 2011 (Figure 1, p. 3); (C) based on information from the International Organization for Migration in Haiti (2013).

Figure 4. Internally displaced persons (IDPs). (A) Estimated number of internally displaced persons in Haiti, July 2010-March 2013. During this interval, the number of IDPs fell from 1.5 million to 320,000 . About the time of the outbreak of cholera in October 2010, there were $>1.0$ million IDPs. Most of these were in Port-au-Prince and adjacent communes that had been severely affected by the earthquake; see Figure 3. (B) Internal migration following the 12 January 2010 earthquake. Only migrants using Government of Haiti transportation are recorded in these figures; those using private transportation are not included. Sources: (A) data from International Organization for Migration in Haiti (2013, Graph 1, 3); (B) data from United States Agency for International Development (2010).

Figure 5. Water and sanitation in IDP camps, Haiti, July 2010-March 2013. (A) Estimated number of IDPs in camps with no toilet facilities, bathing facilities and water provision. (B) Estimated number of camps with no toilet facilities, bathing facilities and water provision. Source: data from International Organization for Migration in Haiti (2013).

Figure 6. The initial diffusion of epidemic cholera in Haiti, October-November 2010. The vectors show the inferred route of cholera transmission in the early stages of the observed epidemic. (A) The postulated source of the epidemic at a United Nations Stabilization Mission in Haiti (MINUSTAH) camp, located to the south of the town of Mirebalais in Centre Department. V. cholerae was carried along the Meye River to Mirebalais, where cases of the disease were admitted to hospital from the evening of 17 October. (B) From Mirebalais, the Artibonite River carried V. cholerae downstream into Artibonite Department and on to the Artibonite River delta area. (C) Spatio-temporal clusters of cholera, October- 
November. The clusters and associated timings are based on the analysis of Piarroux et al. (2011). (D) Locational map of enlargements A-C. Source: maps (A) and (B) based on evidence in Cravioto et al. (2011); the clusters in map (C) are based on Piarroux et al. (2011, Figure 3, 1165).

Figure 7. Inter-department spread of the cholera epidemic in Haiti, October 2010-March 2013. (A) The maps are based on the results of the cross-correlation analysis and link each department to the department with which it shared the highest association. The information is shown for all cholera cases (maps i and ii) and hospitalized cholera cases (maps iii and iv), with the map pairings based on analysis using raw (maps i and iii) and first differenced (maps ii and iv) time series. Vector widths define the strengths of the associations between departments. In-phase (reciprocal links; $k=0$ ) and out-of-phase (unidirectional links; $k \neq 0$ ) are plotted. Vector colours define the lags, $k$. (B) Schematic model of the cholera outbreak, showing the pattern of diffusion between the main diffusion poles in the epidemic. (C) Topographical, hydrological and transport map of Haiti.

Figure 8. Internal coherence of epidemic cholera in the departments of Haiti, May 2011March 2013. The choropleth shading categories indicate the level ( $\bar{r})$ of coherence. (A) All cholera cases. (B) Hospitalized cholera cases. 
Annals of the Association of American Geographers, forthcoming (accepted 26 January 2015)

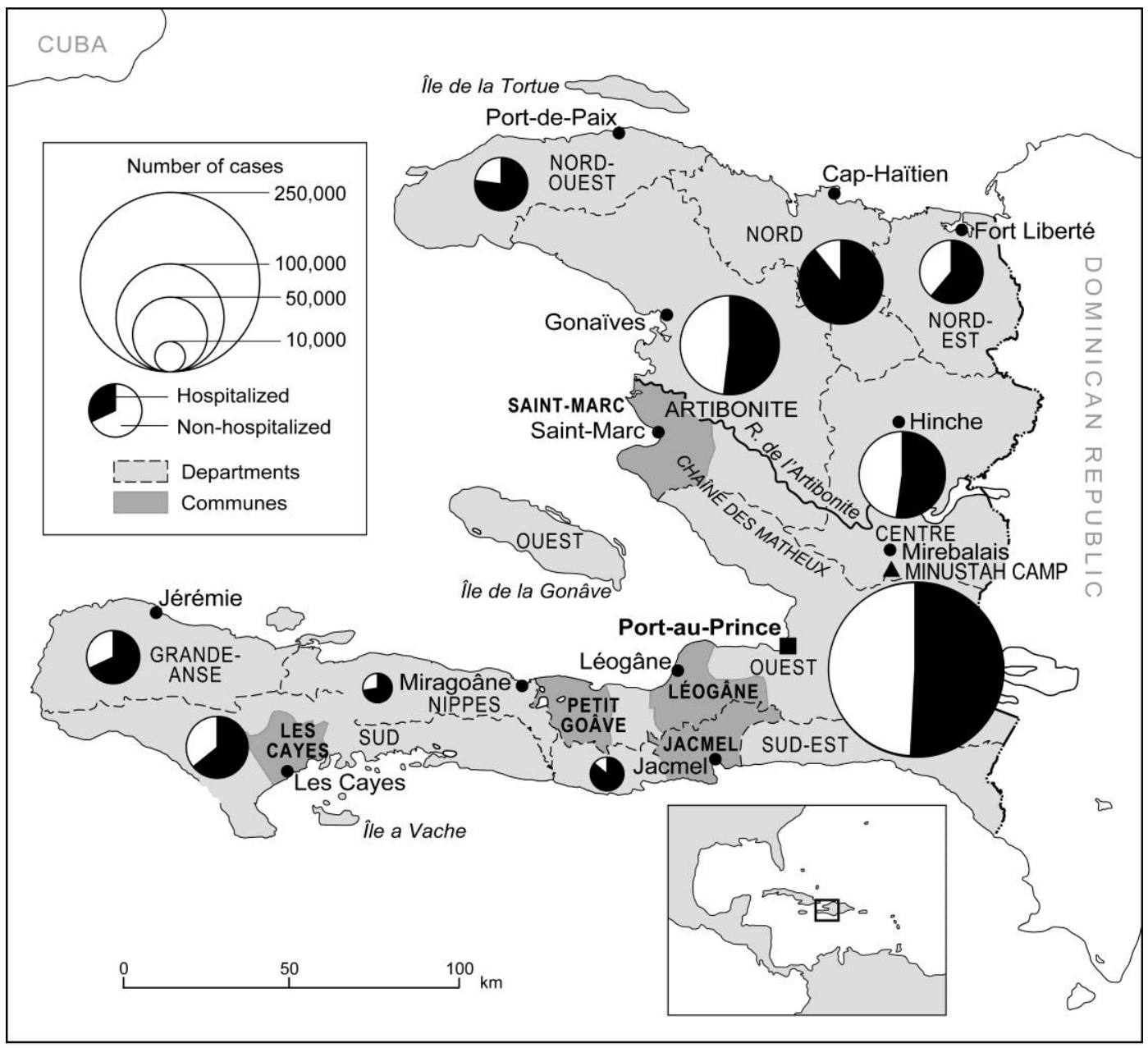

Figure 01

Figure 1 
Annals of the Association of American Geographers, forthcoming (accepted 26 January 2015)

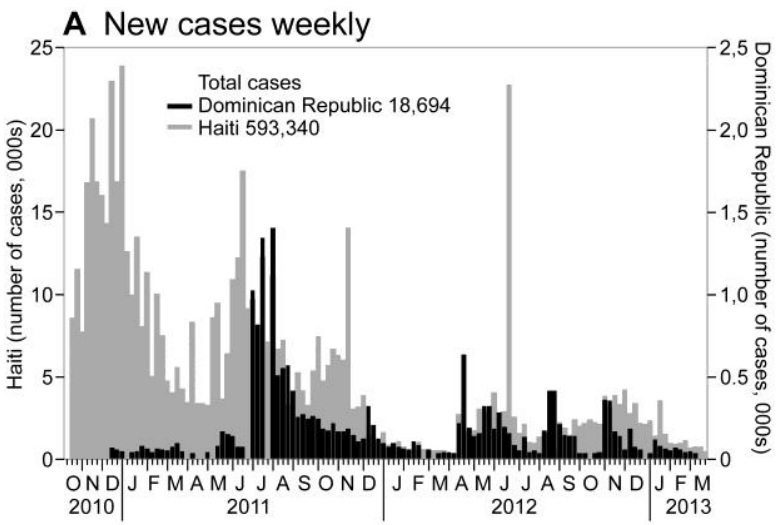

B Weekly case rate per 100,000 population

${ }_{8}$ C Weekly death rate per 100 cases
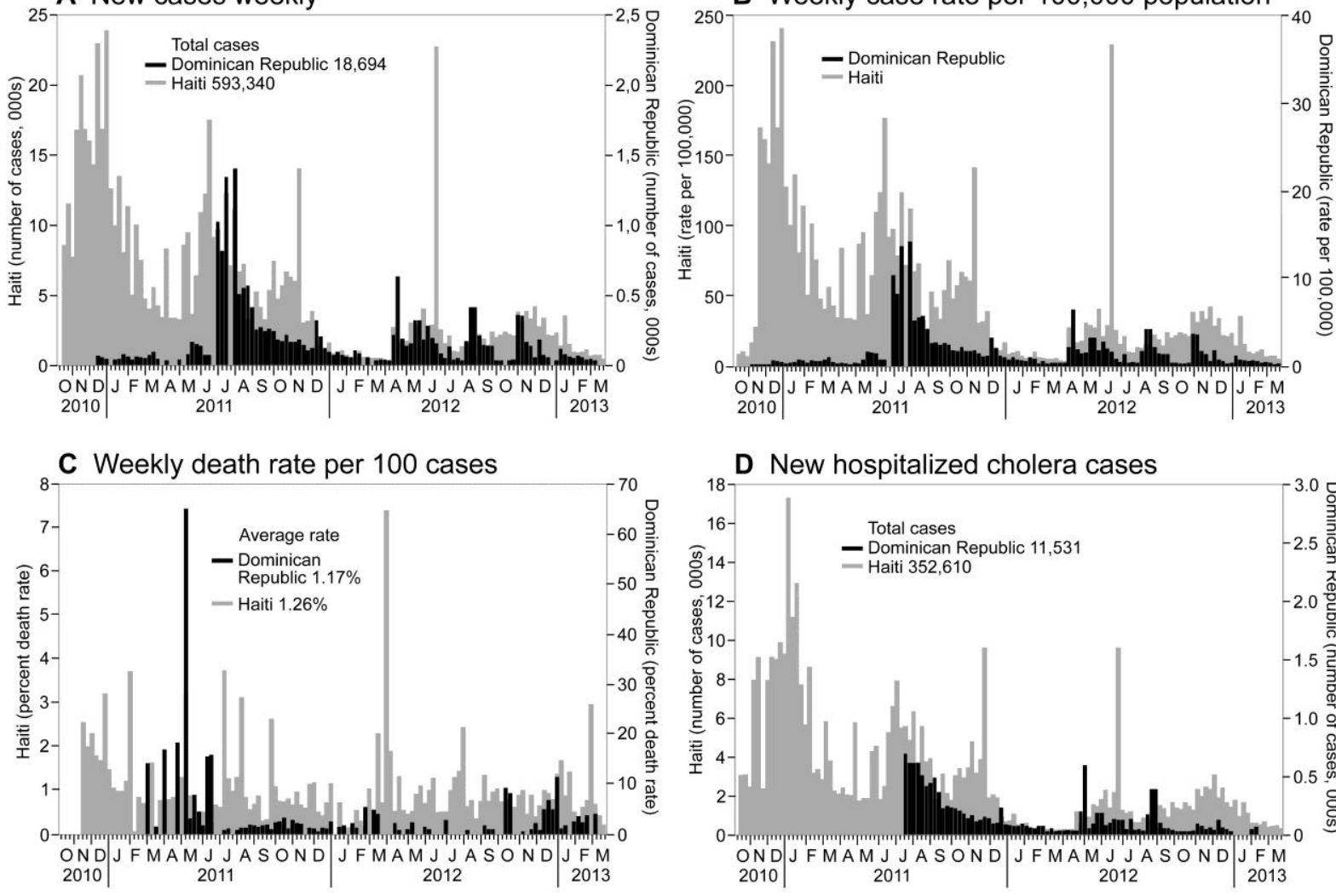

D New hospitalized cholera cases

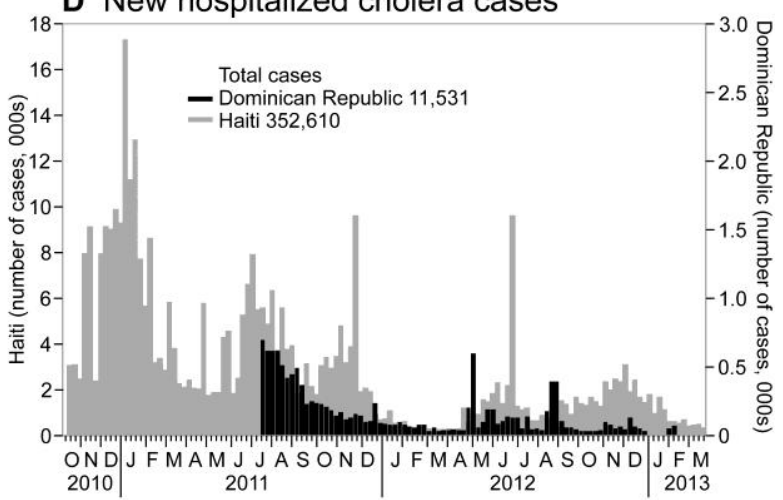

Figure 02

Figure 2 
Annals of the Association of American Geographers, forthcoming (accepted 26 January 2015)

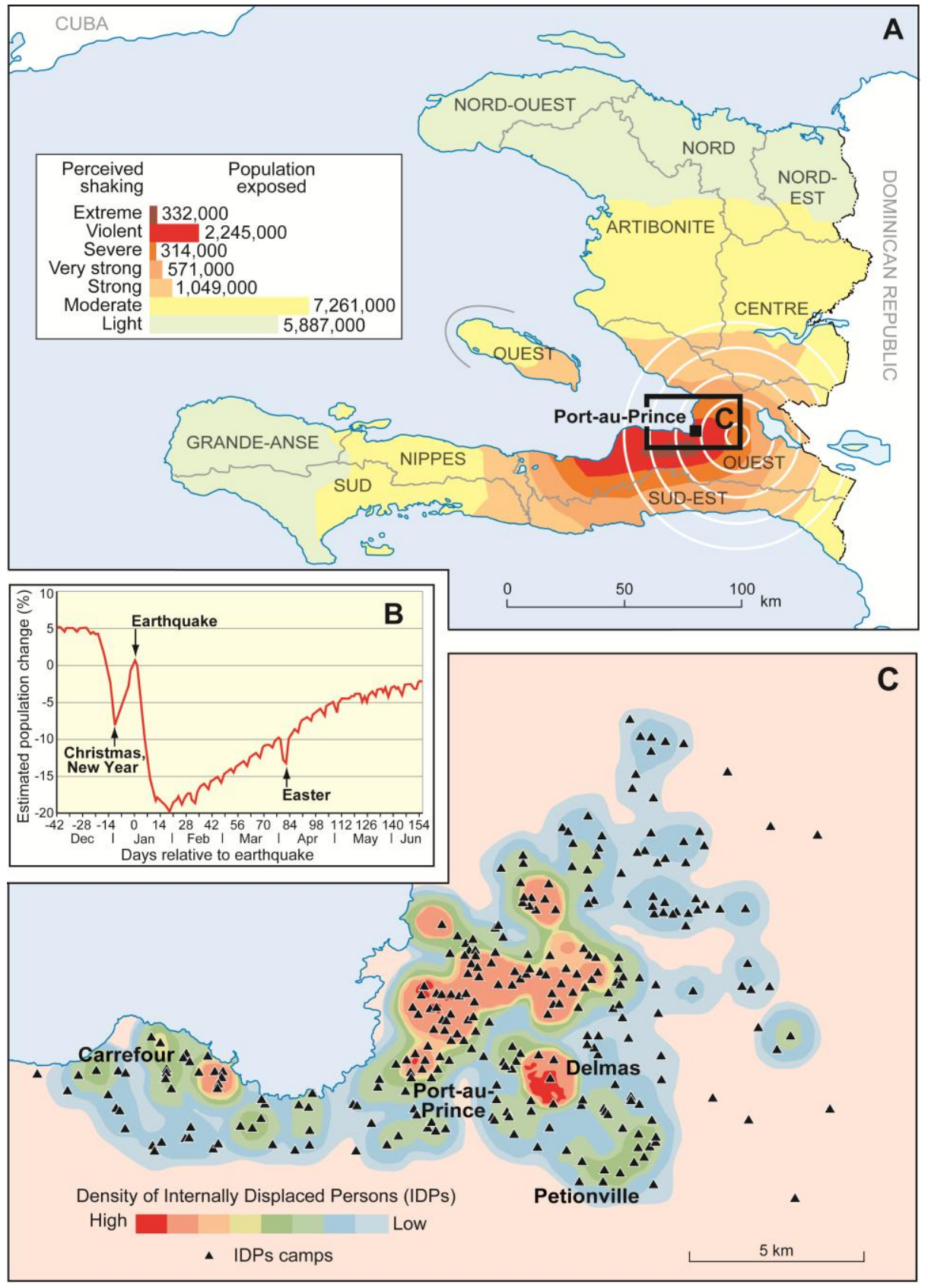

Figure 03

Figure 3 
Annals of the Association of American Geographers, forthcoming (accepted 26 January 2015)

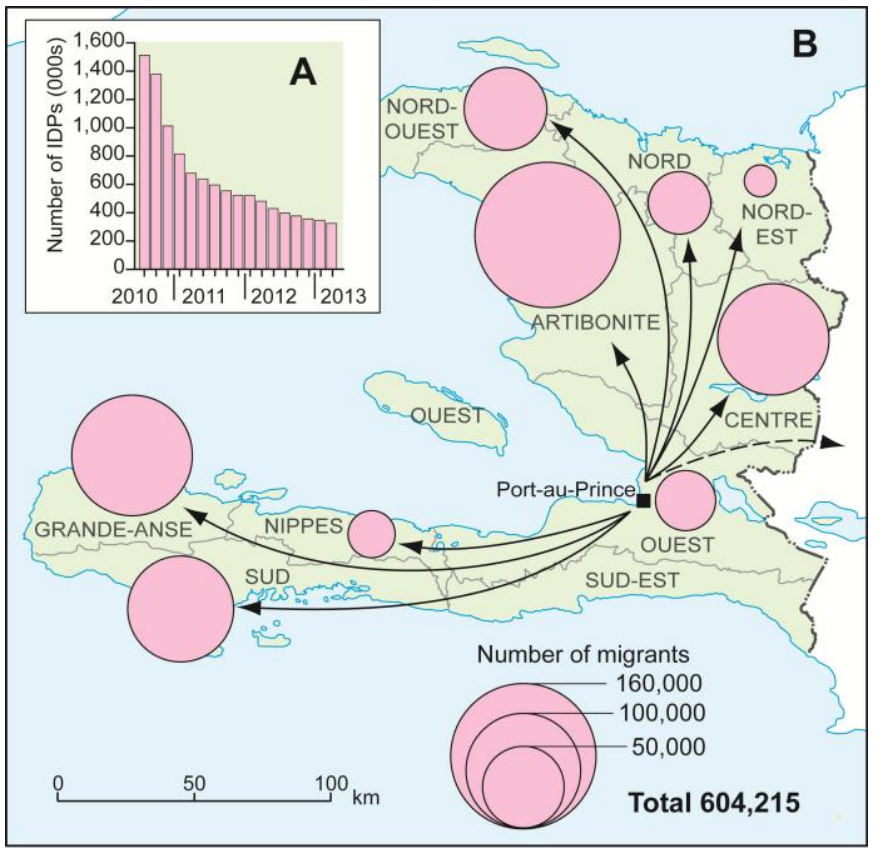

Figure 04

Figure 4 
Annals of the Association of American Geographers, forthcoming (accepted 26 January 2015)
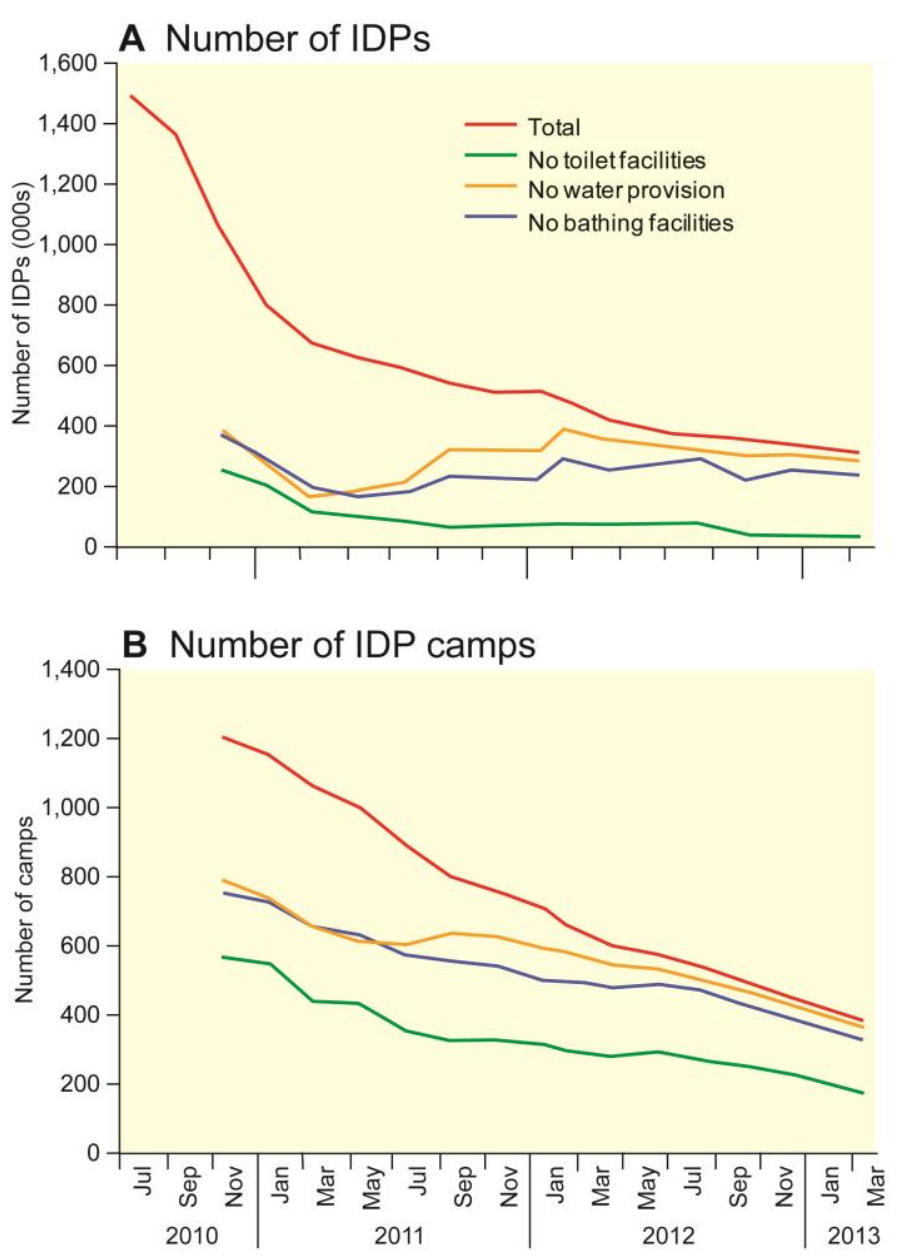

Figure 05

Figure 5 
Annals of the Association of American Geographers, forthcoming (accepted 26 January 2015)
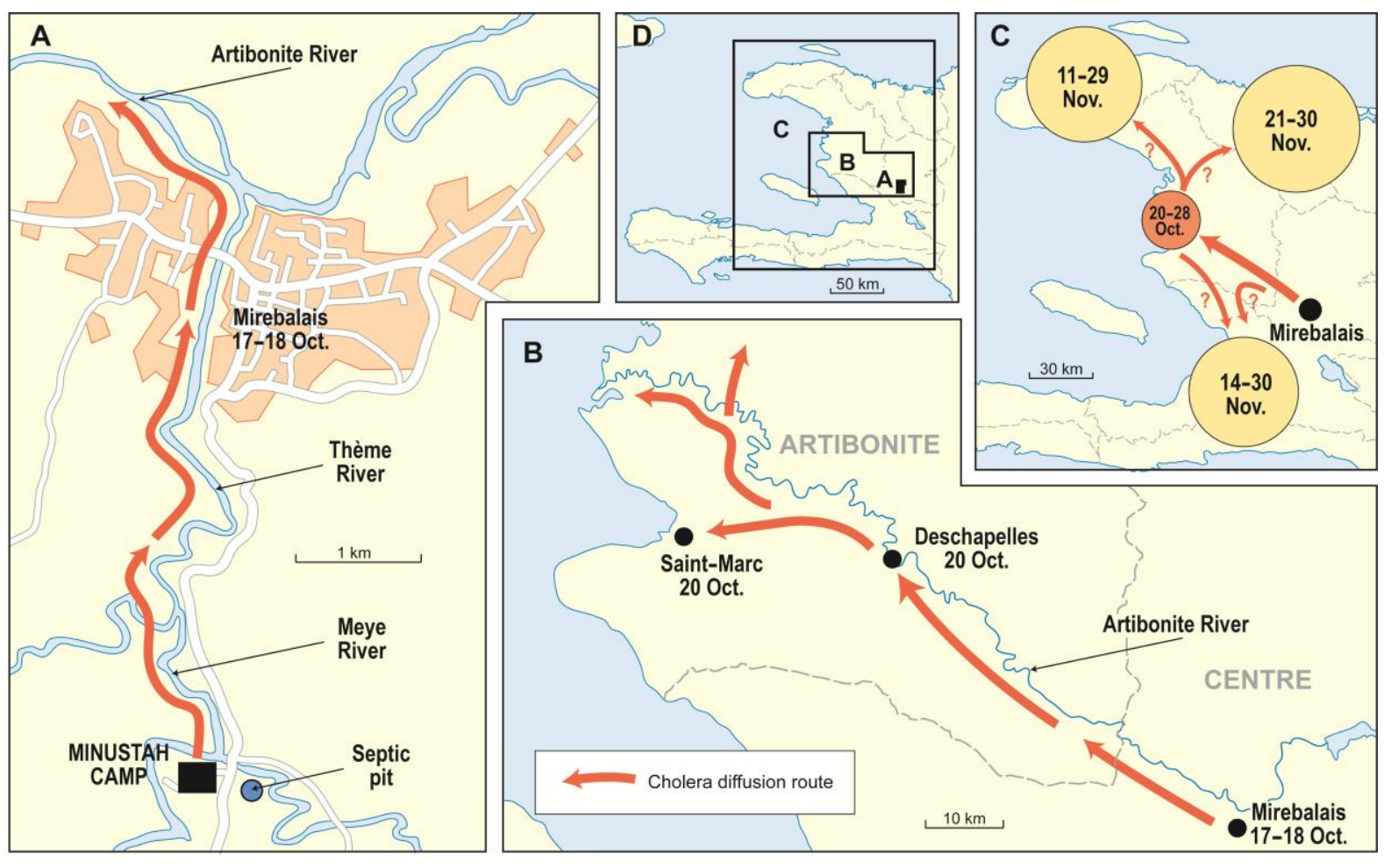

Figure 06

Figure 6 
Annals of the Association of American Geographers, forthcoming (accepted 26 January 2015)

A Strongest correlations between departments
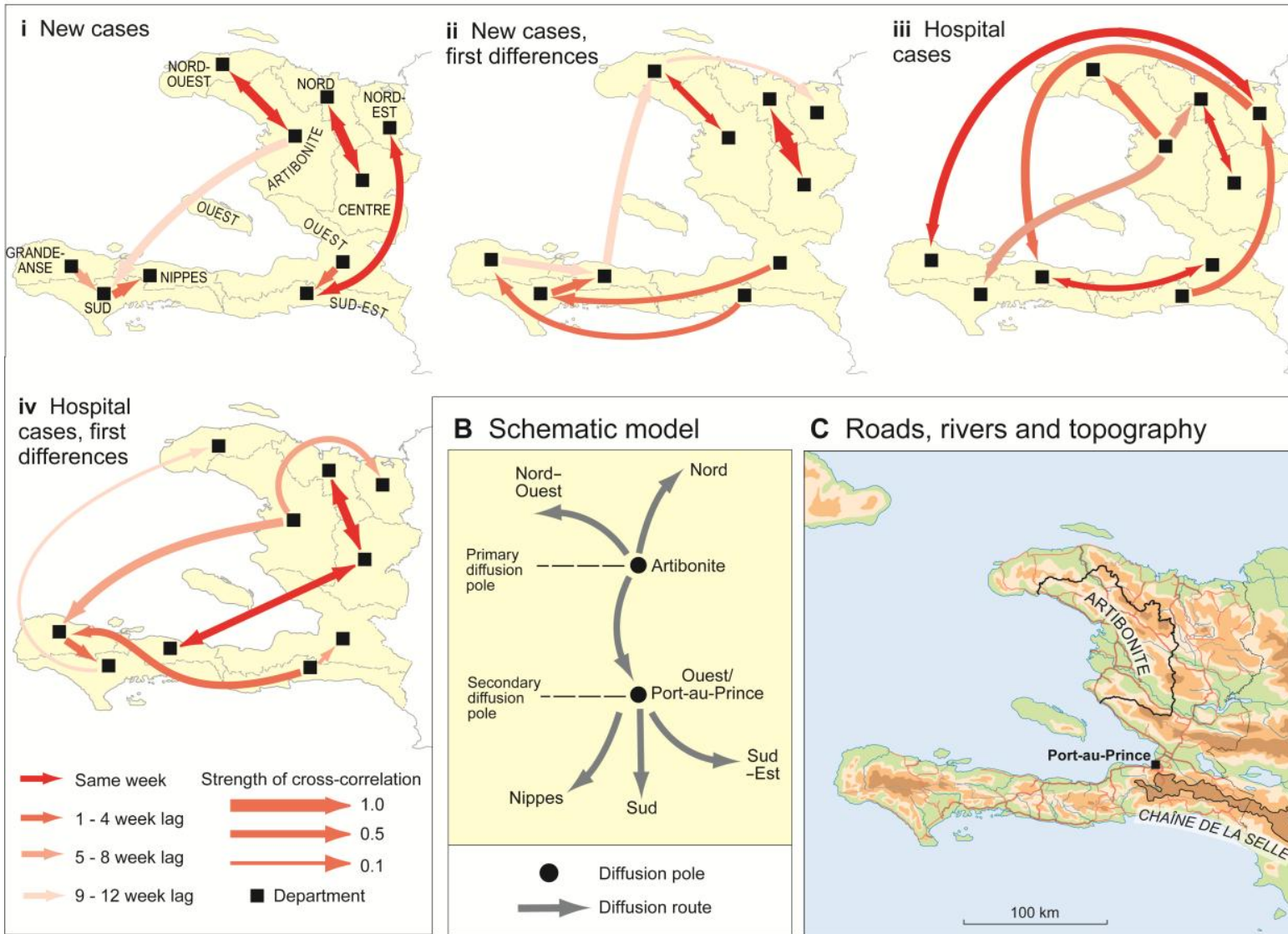

B Schematic model

C Roads, rivers and topography
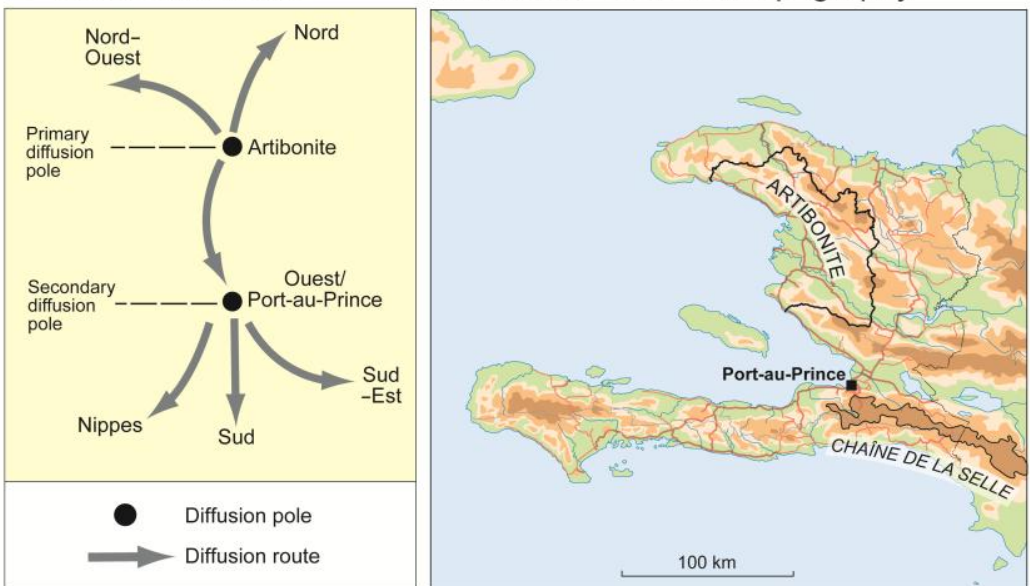

Figure 7 
Annals of the Association of American Geographers, forthcoming (accepted 26 January 2015)

A All cases

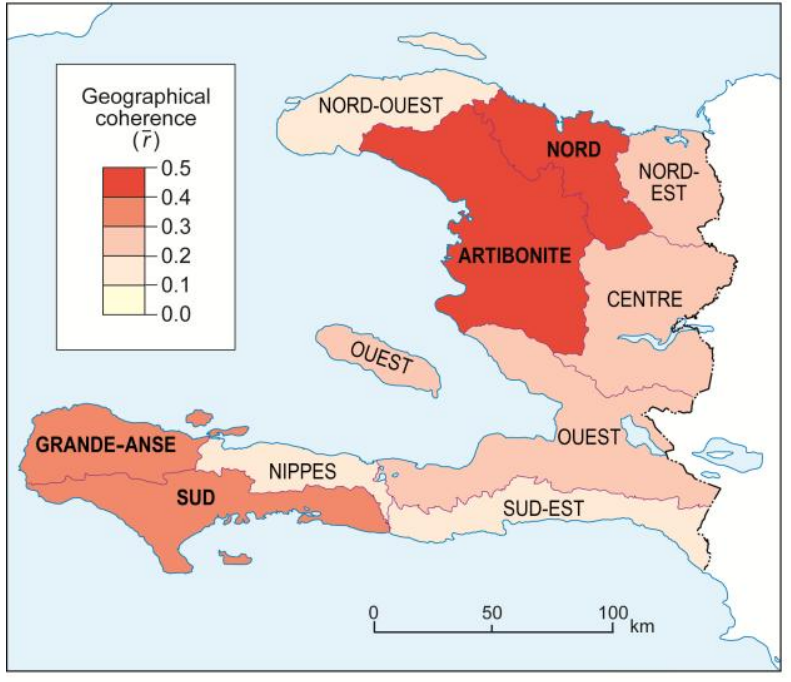

Figure 08
B Hospitalized cases

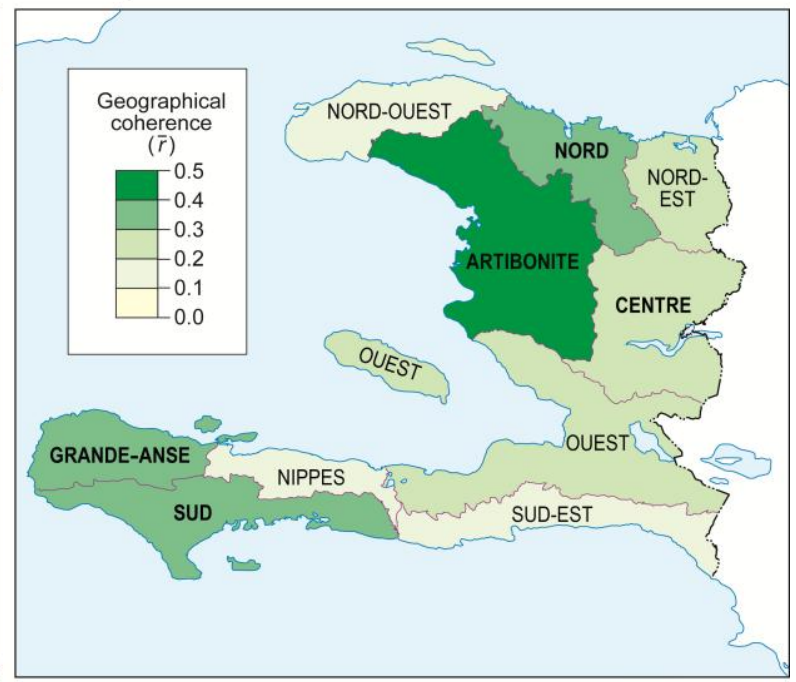

Figure 8 